\title{
Climatic shifts
}

Climates of Hunger: Mankind and the World's Changing Weather. By Reid A. Bryson and Thomas J. Murray. Pp. xv + 171. (American University Publishers Group: London, 1977.) £6.75.

PROFESSOR BRYSON is perhaps the leading proponent of the view that anthropogenic pollution of the atmosphere is hastening the world into a pronounced cooling-at least, a little Ice Age-through the effect of aerosol particles blocking out some of the heat from the Sun. Thomas Murray is a science writer who has worked with the University of Wisconsin-Madison, where Bryson's Institute for Environmental Sciences is based. Working in harness, they have produced a book about the possible hazard to world food supplies of a significant global cooling, but one which is aimed very clearly at the general reader and the non-scientist, including, perhaps, those with some political influence on the world food situation.

The result is a very easy, even glib, read, which is strong on anecdotal material about the impact of past climatic shifts on human societies, but is weak on mechanisms of climatic change and which has no real scientific depth. It was clearly written for a purpose, to spread the message of Bryson's ideas beyond his peer group of climatologists, and even beyond the scientific ranks of those who, for example, regularly read Nature. It does the intended job well, as indicated by the selection of the book as a US Book-of-the-Month Club choice, but this means that someone who is a regular reader of Nature need feel no compunction to rush out and buy the book, but can safely wait for a paperback without missing any significant new contribution from Bryson.

This is very much a Bryson's eyeview; the casual reader will not get a balanced picture of the current climatic debate, but that is of far less importance than interesting such a reader in the debate in the first place. The balance, or lack of balance, is indicated by the reference list, where no less than $25 \%$ of the 80 -odd works cited are authored or co-authored by Bryson.

The most notable omission from that reference list is Stephen Schneider's The Gonesis Strategy (reviewed in Nature 264, 137; 11 November 1976) which is still, to my mind, the best introduction to climatic change for the non-specialist. The gaps in the text of this new book which make it unsuitable as introductory reading in an academic context are typified by the devotion of only four short paragraphs to solar changes, within a mere nine-page chapter "How Climate Changes".

But the importance of all books of this kind is that they draw attention to the possibility of irregular fluctuations in natural forces which can affect world food production. The fact that the world could feed twice the present population, but yet people are starving today, indicates that something is wrong with the overall production and distribution of food. When reserve stocks are deliberately kept low to

John Gribbin

\section{Dissipative structures}

Self-Organisation in Non-Equilibrium Systems: From Dissipative Structure to Order through Fluctuations. By G. Nicolis and I. Prigogine. Pp. xiii +492. (Wiley-Interscience: New York and London, 1977.) £20; \$34.

THE central key word of the monograph by Nicolis and Prigogine is Dissipative Structure. This concept already seems to have become a paradigm, at least in theoretical biology. What is a dissipative structure? The formation of flow structures in physical systems under certain conditions is commonly known. The most frequently quoted dynamic pattern of this type is the Bénard honeycomb-like structure of a liquid heated from below; this phenomenon results from the coupling of heat flow and local convection currents. A further impressive example for spatial and temporal order in a flow structure is the Belousov-Zhabotinski reaction; here, it is the interplay between chemical reactions and diffusion that creates periodic patterns in time and space. Such flow structures exist only within certain boundary conditions and survive only on energy input dissipated in the maintenance of the flow pattern.

Such close similarities exist between the behaviour of a dissipative structure and the properties of living organisms that it is intriguing to investigate living maintain prices on world markets, the prospect of a run of bad harvests is grim, whether or not you subscribe to Bryson's detailed views on why such a pattern of events may take place. Any book which may encourage more sensible husbandry must be welcomed; I hope, however, that the likely success of this little book in its evangelical role will encourage Professor Bryson to provide us with something more technical which we can get our teeth into. The importance of his ideas certainly justifies the devotion of a major text to their display in the academic market place.

John Gribbin is a Fellow of the Science Policy Research Unit, University of Sussex, UK. organisations in terms of flow interactions. The 'bioflows' are, of course, not heat flows or rarely convection flows, but the rates of coupled biochemical reactions and diffusion processes in the open systems of biology. It does seem very exciting to find out whether the various flow patterns observed in chemistry and biology are based on one and the same fundamental principle of coupling between chemical reactivity and diffusional propagation.

The book by Nicolis and Prigogine presents a concise introduction to theoretical foundations and applications of new concepts and offers to approach flow phenomena programmatically in the framework of a general dynamic theory. This introduction to the theory of dissipative structures aims at a better understanding of the evolution and survival of self-organising systems in physics and biology.

Dissipative structures have been recognised to exist only far from equilibrium where the relationships between flows and driving forces are non-linear. Thus, classical non-equilibrium thermodynamics (relating flows and potential gradients linearly) do not provide adequate tools to describe dissipative flow structures. Among the new concepts introduced by the Brussels school is the definition of a local potential which generalises the familiar cheni- 